\title{
Spine Cryoablation: Pain Palliation and Local Tumor Control for Vertebral Metastases
}

\author{
(D) A. Tomasian, (D) A. Wallace, (DB. Northrup, (D).J. Hillen, and (D).W. Jennings
}

\section{ABSTRACT}

BACKGROUND AND PURPOSE: Percutaneous cryoablation has emerged as a minimally invasive technique for the management of osseous metastases. The purpose of this study was to assess the safety and effectiveness of percutaneous imaging-guided spine cryoablation for pain palliation and local tumor control for vertebral metastases.

MATERIALS AND METHODS: Imaging-guided spine cryoablation was performed in 14 patients (31 tumors) with vertebral metastases refractory to conventional chemoradiation therapy or analgesics, to achieve pain palliation and local tumor control in this retrospective study. Spinal nerve and soft-tissue thermal protection techniques were implemented in all ablations. Patient response was evaluated by a pain numeric rating scale administered before the procedure and 1 week, 1 month, and 3 months after the procedure. Pre- and postprocedural analgesic requirements (expressed as morphine-equivalent dosages) were also analyzed at the same time points. Pre- and postprocedural cross-sectional imaging was evaluated in all patients to assess local control (no radiographic evidence of disease at the treated sites). Complications were monitored. Analysis of the primary end points was undertaken via paired-comparison procedures by using the Wilcoxon signed rank test.

RESULTS: Thirty-one tumors were ablated in 14 patients ( 9 women and 5 men; $20-73$ years of age; mean age, 53 years). The most common tumor location was in the lumbar spine ( $n=14,45 \%)$, followed by the thoracic spine ( $n=8,26 \%)$, sacrum $(n=6,19 \%)$, coccyx ( $n=2,6 \%)$, and cervical spine $(n=1,3 \%)$. There were statistically significant decreases in the median numeric rating scale score and analgesic usage at 1-week, 1-month, and 3-month time points ( $P<.001$ for all). Local tumor control was achieved in 96.7\% (30/31) of tumors (median follow-up, 10 months). Two patients had transient postprocedural unilateral lower extremity radiculopathy and weakness.

CONCLUSIONS: Percutaneous imaging-guided spine cryoablation is a safe and effective treatment for pain palliation and local tumor control for vertebral metastases.

ABBREVIATIONS: NRS = numeric rating scale; RFA = radiofrequency ablation

$\mathrm{T}$ he vertebral column is the most common site for bone metastases, with an incidence of $30 \%-70 \%$ in patients with metastatic cancer, and is a major cause of morbidity in these patients. $^{1-3}$

The current standard of care for the management of painful osseous metastases is external beam radiation. ${ }^{4}$ Generally, external beam radiation achieves at least partial pain palliation, but often, there is a delay in the relief of symptoms. ${ }^{5}$ In addition, painful osseous metastatic disease is often refractory to systemic

Received April 14, 2015; accepted after revision May 26.

From the Mallinckrodt Institute of Radiology, Washington University School of Medicine, St Louis, Missouri.

Please address correspondence to Anderanik Tomasian, MD, Mallinckrodt Institute of Radiology, Washington University School of Medicine, 510 South Kingshighway Blvd, St Louis, MO 63110; e-mail: tomasian.andy@gmail.com

http://dx.doi.org/10.3174/ajnr.A4521 therapies such as chemotherapy, hormonal therapy, radiopharmaceuticals, and bisphosphonates. ${ }^{6}$ Surgical intervention is of limited value in patients with spinal metastases, owing to its morbidity and the often poor functional status and short life span of the patients, and is typically reserved for lesions with consequent neurologic compromise or spinal instability. Pain palliation with systemic analgesics, including nonsteroidal anti-inflammatory drugs and opioids, remains the only alternative option for many patients. $^{7}$

Investigators have explored several alternative strategies for the treatment of painful metastases, including minimally invasive percutaneous imaging-guided tissue ablative methods using ethanol, ${ }^{8}$ laser-induced interstitial thermotherapy, ${ }^{9}$ radiofrequency ablation (RFA), ${ }^{10-13}$ and, most recently, cryoablation. ${ }^{14-23}$ Two multicenter clinical trials have demonstrated that percutaneous RFA is effective in reducing pain due to osseous metastatic dis- 
ease. $^{12,13}$ Although effective at reducing pain, RFA has important limitations, including nonvisualization of the ablation margin with CT, pain associated with the procedure, and, frequently, increased pain during the immediate posttreatment period.

Similar to RFA, an important limitation of microwave ablation is nonvisualization of the ablation zone with CT. In contrast to RFA or microwave ablation, cryoablation results in formation of a hypoattenuating ice ball, which is readily identified by CT, beyond which tissues are safe from thermal injury. ${ }^{24}$ Additional advantages of cryoablation compared with RFA or microwave ablation are decreased intraprocedural and postprocedural pain, the ability to use multiple probes in various orientations to achieve additive overlapping ablation zones, ${ }^{6,18}$ and efficiency in the treatment of osteoblastic metastases when high impedance often renders RFA ineffective.

The purpose of this single-center study was to retrospectively evaluate the safety and effectiveness of percutaneous imagingguided spine cryoablation for pain palliation and local tumor control for patients with painful vertebral metastatic disease.

\section{MATERIALS AND METHODS}

This retrospective study was approved by our institutional review board and was Health Insurance Portability and Accountability Act-compliant. Consent was waived for retrospective study participation. Percutaneous imaging-guided cryoablation of 31 vertebral metastases was performed in 14 patients with lesions refractory to conventional chemotherapy, radiation therapy, and analgesics following interdisciplinary consultation in the setting of a committee involving medical oncologists, radiation oncologists, surgical oncologists, and interventional musculoskeletal radiologists. Resistance to radiation therapy and chemotherapy was determined by the radiation oncologists and medical oncologists, respectively. Only patients with substantial pain as indicated by a score of at least 4 on a scale of $0-10$ for the question "Please rate your pain by circling the one number that best describes your worst pain over the past 24 hours" were treated. ${ }^{25}$ Informed consent for the procedure was obtained from all patients. The study population included 9 women and 5 men with a mean age of 53 years (range, $20-73$ years).

The most common primary tumor was lung cancer in 4 patients $(28.5 \%)$ and colorectal carcinoma in 3 patients $(21.5 \%)$. Other tumors included breast cancer and follicular thyroid carcinoma in 2 patients each (14\%) and head and neck squamous cell carcinoma, pancreatic adenocarcinoma, and epithelioid hemangioendothelioma in 1 patient each (7\%). Eighteen of 31 lesions underwent directed optimized radiation therapy before the cryoablation procedure, ranging from 28 months to 1 month before the procedure. Preprocedural imaging studies were reviewed in all patients for ablation planning. Postcryoablation MR imaging and PET/CT imaging were available for all patients (range, 1-24 months following the procedures) and were evaluated to determine the following: 1) the extent of ablation and degree of local tumor control, 2) baseline for subsequent PET/CT or MR imaging and the potential cryoablation retreatment, and 3) possible complications. Postablation imaging was independently reviewed by 2 attending interventional musculoskeletal radiologists (J.W.J. and T.J.H.) for all patients and agreement regarding local tumor control was achieved on consensus. Local tumor control was defined as no radiographic evidence of active tumor based on the following criteria: 1) no new or residual nodular or masslike enhancement in the ablation bed, and 2) lack of hypermetabolism in the ablation bed on PET/CT.

\section{Cryoablation Procedure}

The procedures were performed with the patient under conscious sedation in 13 patients (28 lesions) and under general anesthesia in 1 patient ( 3 lesions) by 2 interventional musculoskeletal radiologists (J.W.J. and T.J.H.) with 10 and 5 years of spine ablation experience, respectively. CT was used for imaging guidance in all patients. Local and periosteal anesthesia was achieved with a combination of $1 \%$ lidocaine and $0.25 \%$ bupivacaine for all patients.

Cryoablation was performed on each lesion following coaxial (bone component) or single-axial (soft-tissue component or bone-soft tissue interface) placement of Endocare (HealthTronics, Austin, Texas) or Galil (Galil Medical, Yokneam, Israel) cryoprobes. Cryoprobe type, number of probes, duration of the ablation cycle, number of ablations, and the percutaneous approach were preoperatively determined by the operator in each individual case on the basis of tumor size, location, and goal of therapy. The vertebral body lesions were accessed by using a unipedicular or bipedicular approach, depending on the size of the lesion. A bipedicular approach was used if the lesion involved $>50 \%$ of the vertebral body width. The vertebral posterior element lesions and sacrococcygeal lesions were accessed directly. The Galil cryoprobes used were 13-17 ga with predicted ablation zones ranging from $2 \times 1$ to $4 \times 2 \mathrm{~cm}$ in diameter at $-40^{\circ} \mathrm{C}$. The Endocare Perc-15 and Perc-17 (both $1.7 \mathrm{~mm}$ in diameter) were used with predicted ablation zones of $15 \times 15$ and $15 \times 35 \mathrm{~mm}$ at $-40^{\circ} \mathrm{C}$, respectively. At least 1 freeze/active thaw/freeze cycle was performed on each lesion, with duration times of at least 10 minutes, 5 minutes, and 10 minutes, respectively. Intraprocedural ablation imaging was performed at 5- and 10-minute intervals during the freeze cycles. Ice ball size and extent were evaluated on standard body (window of $400 \mathrm{HU}$ and level of $40 \mathrm{HU}$ ) settings on unenhanced CT as a hypoattenuating region arising from the probe tips to envelope the neoplastic tissue.

With primarily osteolytic lesions, the hypoattenuating ice ball was clearly visualized and used to determine the adequacy of ablation. With primarily osteoblastic lesions and lack of a large lytic component, the intraosseous ice ball was not well seen. The size of the ablation zone was determined by a combination of the hypoattenuating ice ball extending beyond the cortex and preclinical testing data demonstrating ice ball size with a given cryoprobe. The duration of the freezing portion of the ablation cycle was adjusted on the basis of the adequacy of lesion coverage and the proximity of adjacent critical structures on interval imaging. There were no probe manipulations between cycles.

\section{Thermal Protection Techniques}

Neuroforaminal thermal monitoring was performed in all cases, owing to the close proximity of the neural foramen and/or central canal to the margins of the ablation zone. Neural thermal protection techniques involving epidural or neuroforaminal injection of 

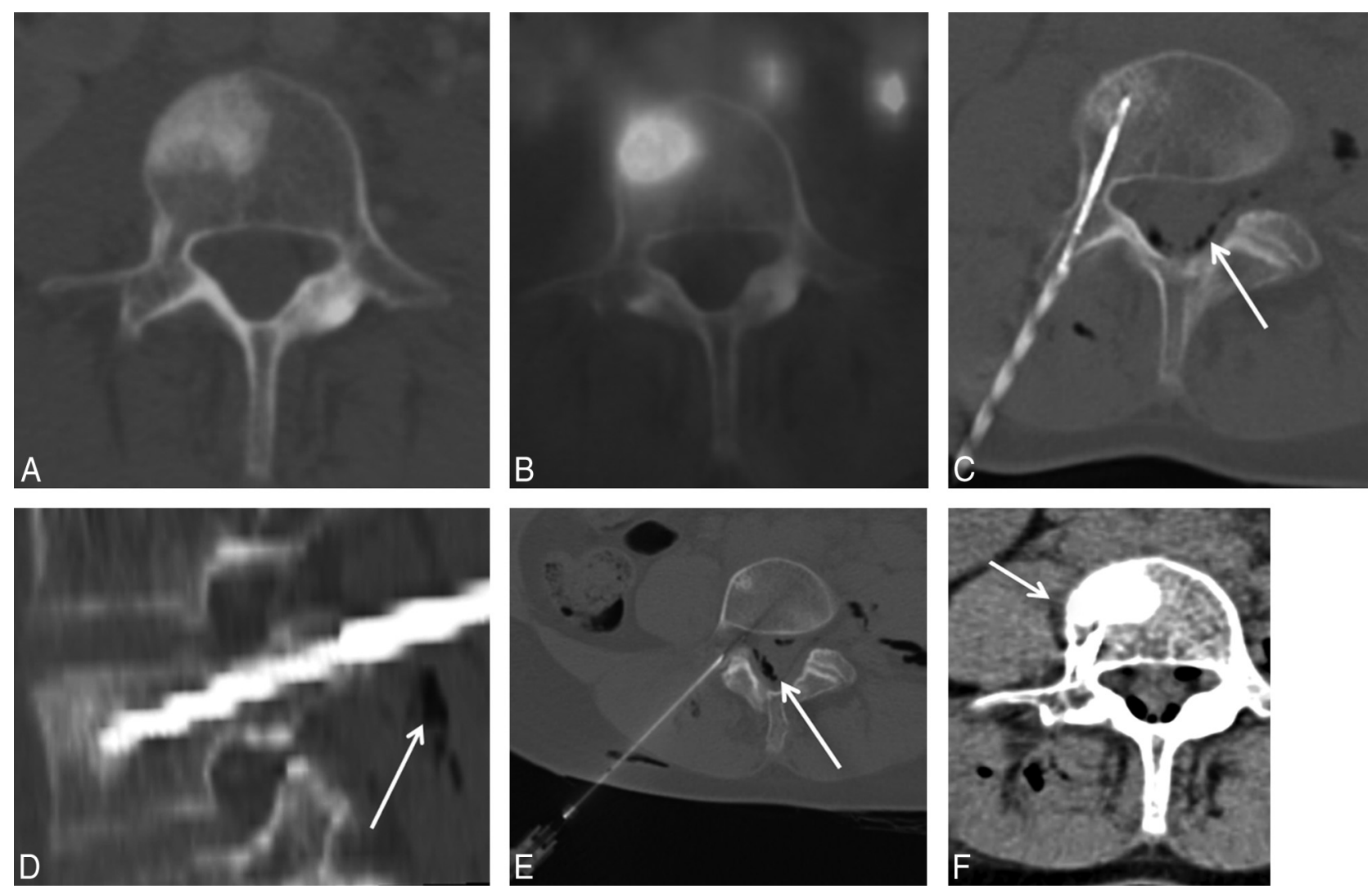

FIG 1. A 59-year-old woman with non-small cell lung cancer and painful osteoblastic L4 vertebral body metastasis. Transaxial CT (A) and FDG PET/CT (B) images demonstrate a hypermetabolic osteoblastic L4 vertebral body metastasis. Transaxial (C) and sagittal (D) intraprocedural CT images demonstrate coaxial placement of a single Ice Rod Plus 17-gauge cryoprobe (Galil) within the L4 sclerotic lesion via a right transpedicular approach. To achieve thermal protection, an 18-ga spinal needle is placed at the right L4 L5 neuroforamen ( $E$ ), and carbon dioxide is injected in the neuroforamen and epidural space before cryoablation ( $C-E$, arrows). Postablation $C T$ demonstrates a thin rim of hypoattenuating ice ball extending beyond intact vertebral body cortex ( $F$, arrow), marking the margin of the ablation zone.

carbon dioxide or warmed 5\% dextrose water were implemented. This was performed by placing an 18-ga spinal needle (Becton, Dickinson and Company, Franklin Lakes, New Jersey) in the region of the neuroforamen, connected to a Passage Hemostasis Valve (Merit Medical, South Jordan, Utah), and coaxial placement of a thermocouple (St. Jude Medical, St. Paul, Minnesota) into the neuroforamen to measure temperatures. If the temperatures began to approach $10^{\circ} \mathrm{C}$, the thermoprotective agents were injected into the neuroforamen. Because carbon dioxide is one of the most effective thermoprotecive agents, it is always injected first. In addition, thermal protection of abdominal and pelvic soft tissues, including nerves and bowel, was achieved by injection of carbon dioxide via a 22-gauge spinal needle (Becton, Dickinson and Company) placed adjacent to critical structures in close proximity to the ablation zone, and adequacy of thermal protection was verified with CT before cryoablation.

Intraprocedural motor-evoked potential monitoring was performed during 1 ablation, which was performed with the patient under general anesthesia. ${ }^{26,27}$

The cutaneous thermal protection technique consisted of a surface application of warm saline solution in all cases. After ablation, the patients were transferred to a recovery unit for 1 hour of postprocedural observation before being discharged to the patient care division.

\section{Pre- and Posttreatment Patient Assessment}

On the day of the procedure, preprocedural pain was determined by a numeric rating scale (NRS) score (scaled from a minimum of 0 to a maximum of 10), ${ }^{25}$ and analgesic requirements were recorded by the musculoskeletal nurse coordinator. The subsequent NRS scores and analgesic requirements were then obtained by telephone 1 week, 1 month, and 3 months after the procedure by the musculoskeletal nurse coordinator. Patients were asked about potential postprocedural complications, including questions about the wound, nerve pain, and muscle weakness. Chart reviews were also undertaken, and evidence of complications was recorded.

\section{Primary End Points and Statistical Analysis}

The primary end points analyzed were pain relief, analgesic and/or opioid usage, local tumor control on postprocedural cross-sectional imaging, and complication rates. Preprocedural NRS scores and analgesics usage expressed as morphine equivalent dosages by using established tables, ${ }^{28}$ as well as postprocedural NRS scores and analgesics usage at 1 week, 1 month, and 3 month intervals, were analyzed for median differences by using the Wilcoxon signed rank test. Results are reported as median \pm absolute deviation, to analyze the nonnormal data distribution appropriately. Postprocedural cross-sectional imaging was evalu- 

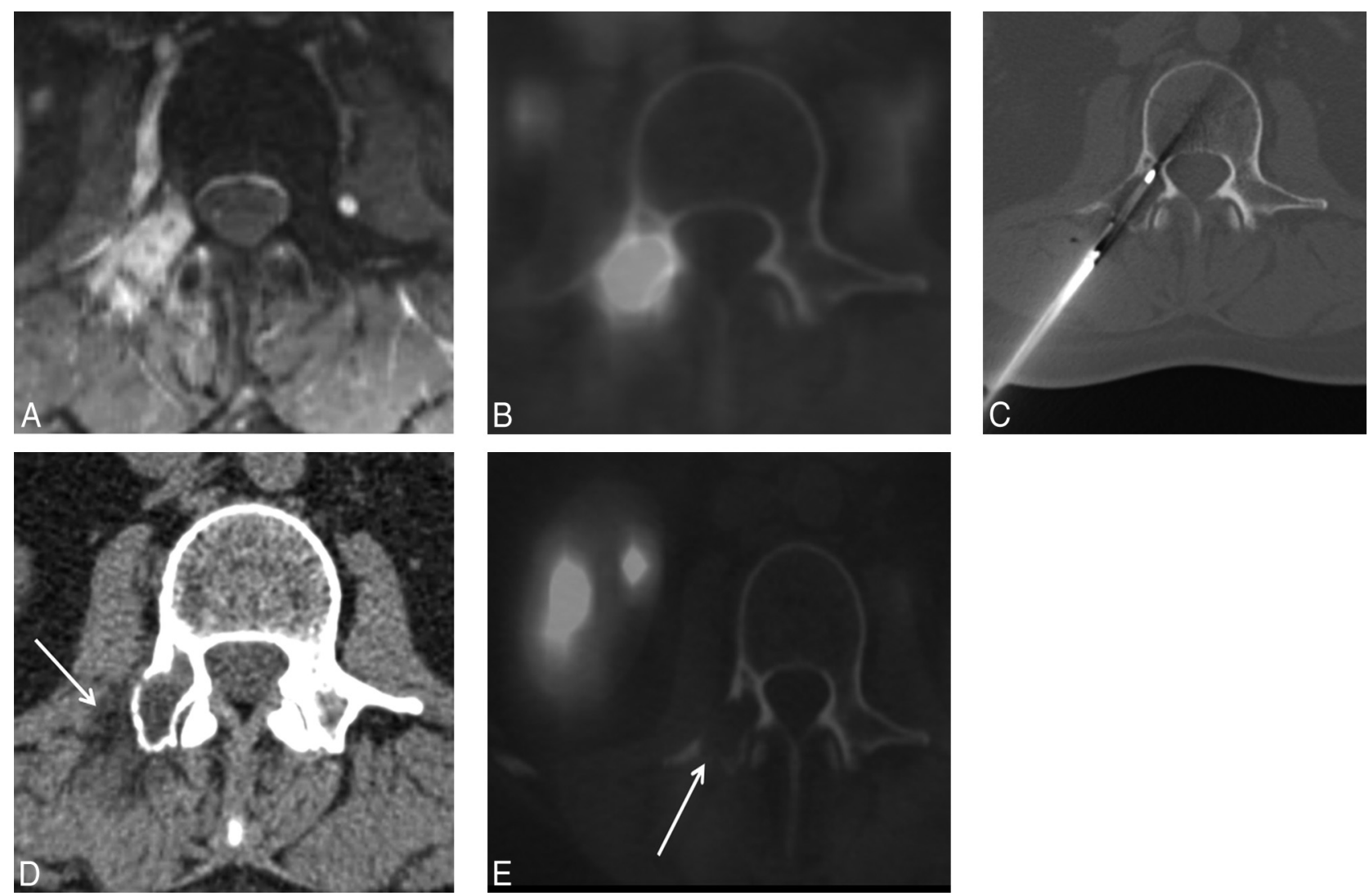

FIG 2. A 54-year-old woman with metastatic breast cancer and painful right L2 pedicle and transverse process osteolytic metastasis. Transaxial T1-weighted fat-saturated postcontrast MR $(A)$ and FDG PET/CT $(B)$ images demonstrate right $L 2$ pedicle and transverse process metastasis that demonstrates homogeneous contrast enhancement and marked FDG uptake. Transaxial CT image (C) demonstrates coaxial placement of the Perc-17 Endocare cryoprobe within the right L2 pedicle and transverse process osteolytic lesion. Postcryoablation transaxial CT image (D) demonstrates the hypoattenuating ice ball encompassing the lesion and extending beyond the cortical margin (arrow). A 14-month postcryoablation FDG PET/CT demonstrates complete local tumor control with no evidence of metabolically active tumor (E, arrow).

ated and compared with preprocedural imaging by the authors to determine local tumor control. Complications were identified and classified according to the Society of Interventional Radiology classification system for complications by outcome. ${ }^{29}$ All statistical analyses were performed by using SPSS Statistics, Release 22.0 (IBM, Armonk, New York). An $\alpha$ value of .05 was statistically significant.

\section{RESULTS}

All cryoablation procedures were performed as preoperatively planned and were technically successful. Thirty-one metachronous tumors (22 osteolytic and 9 osteoblastic lesions) were ablated in 14 patients (Figs 1-3). The most common tumor location was in the lumbar spine $(n=14,45 \%)$, followed by thoracic spine $(n=8,26 \%)$, sacrum $(n=6,19 \%)$, coccyx $(n=2,6 \%)$, and cervical spine $(n=1,3 \%)$. The anatomic locations of treated lesions were in vertebral body (lumbar spine, $n=8$, and thoracic spine, $n=4$ ), pedicle (lumbar spine, $n=3$, and thoracic spine, $n=2$ ), lamina (lumbar spine, $n=2$, and thoracic spine, $n=2$ ), and spinous process (lumbar spine, $n=1$ ). The treated lesion in the cervical spine involved the lamina and spinous process. One lesion underwent cementoplasty (sacrum), and 1 lesion underwent vertebroplasty (lumbar spine) as part of the procedure. According to the Society of Interventional Radiology guidelines, ${ }^{29}$ no major complication, such as permanent neural thermal injury, occurred as a result of the cryoablation procedure. Two of the 14 patients had postprocedural radicular lower extremity nerve pain (a minor complication) and received nerve root steroid and/or anesthetic injections. These patients remained asymptomatic following 1 transforaminal nerve root block (follow-up of 10 and 15 months). Local tumor control (no radiographic evidence of active tumor at the treated sites) was achieved in 96.7\% (30/31) of tumors (median follow-up, 10 months; range, 1-24 months), as evaluated on postprocedural cross-sectional imaging. One patient with sacral metastases developed progression of disease despite technically adequate cryoablation.

\section{Effect of Cryoablation on Patient Pain and Analgesic Use}

There were statistically significant decreases in the median NRS scores at 1 week, 1 month, and 3 months following the procedure $(P<.001$ for all). The preprocedural NRS score was $8 \pm 1$ (median \pm absolute deviation). The postprocedural NRS score at 1-week, 1-month, and 3-month time points was $3 \pm 1$ (median \pm absolute deviation) (Fig 4A). Two patients had slightly improved, but persistent, pain at all postprocedural time points, of whom 1 patient died 5 months after the procedure with progression of disease. There were statistically significant decreases in the median morphine-equivalent dosages at 1-week, 1-month, and 

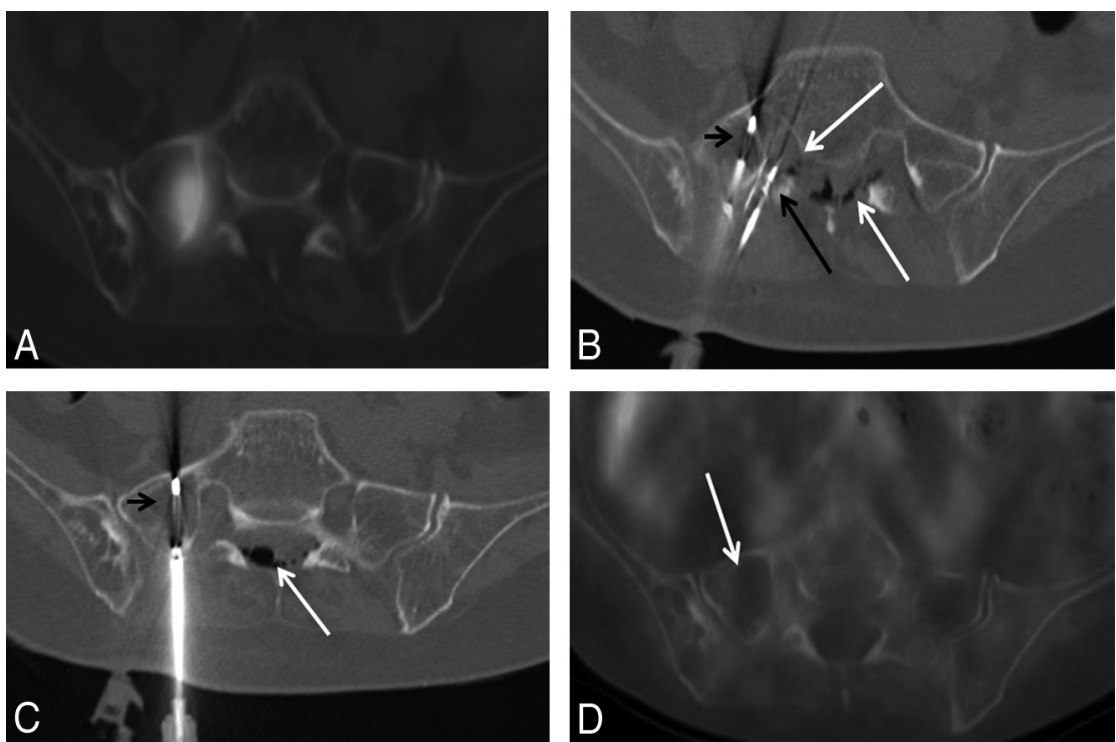

FIG 3. A 69-year-old man with metastatic follicular thyroid carcinoma and painful right $\mathrm{Sl}$ metastasis. Transaxial iodine-131 SPECT CT image demonstrates increased radiopharmaceutical uptake in the right $\mathrm{Sl}$, compatible with metastasis $(A)$. Transaxial intraprocedural $\mathrm{CT}$ images demonstrate coaxial placement of 2 Perc-17 Endocare cryoprobes within the right S1 lesion ( $B$ and $C$, short arrow). Thermal protection is performed by placement of a thermocouple and a spinal needle within the right S1 neuroforamen ( $B$, long black arrow) and injection of carbon dioxide into the right S1 neuroforamen with epidural extension ( $B$ and $C$, white arrows). A 24-month postcryoablation FDG PET/CT demonstrates complete local tumor control with no evidence of metabolically active tumor ( $D$, arrow).
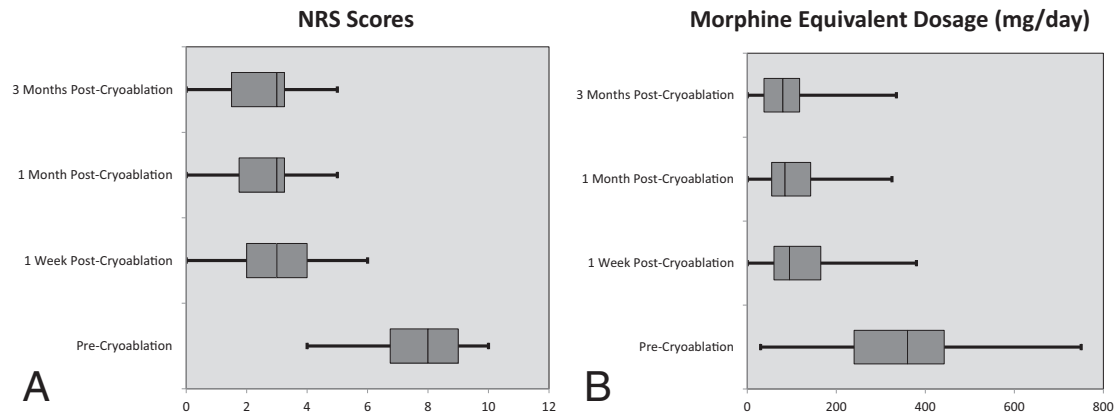

FIG 4. Distribution of NRS scores $(A)$ and morphine-equivalent dosages $(B)$ at study time points. There was a statistically significant decrease in postcryoablation median NRS scores and morphine-equivalent dosages $(P<.001$ for all).

3-month postprocedural time points ( $P<.001$ for all). The preprocedural morphine equivalent dosage was $360 \pm 105 \mathrm{mg} /$ day (median \pm absolute deviation). The postprocedural morphine equivalent dosages at 1 -week, 1 -month, and 3-month time points were $95 \pm 55 \mathrm{mg} /$ day (median \pm absolute deviation), $85 \pm 50$ $\mathrm{mg} /$ day, and $80 \pm 45 \mathrm{mg} /$ day, respectively (Fig $4 B$ ).

\section{DISCUSSION}

Painful vertebral column metastatic disease is a substantial cause of morbidity in patients with cancer owing to its high prevalence, the weight-bearing nature of the spine, and close proximity to critical structures, including the nerve roots and spinal cord. Pain from neoplastic bone involvement in the spine is multifactorial and is a consequence of mechanical factors, including direct involvement of spinal nerve roots and mass effect on the nerve roots and spinal cord, biologic factors including osteoclast-mediated proton sensitization of the sensory fibers at the mineralized bone- tumor interface, sensitization or activation of sensory nerve fibers by products directly produced in tumor and tumor stromal cells, and distortion of mechanosensitive fibers following normal mechanical stress due to loss of tensile strength in the bone secondary to cancer. ${ }^{30-32}$ Goblirsch et al ${ }^{32}$ suggested that reduced tumor burden and reduced osteolysis are important for decreased pain following radiation therapy. As with the creation of pain related to osseous metastatic disease, the mechanism of action and therapeutic effects of cryoablation are likely similar and multifactorial; however, they have not been studied. ${ }^{18}$

While external beam radiation remains the current standard of care for the management of painful osseous metastases, ${ }^{4}$ percutaneous cryoablation has emerged as a safe and effective treatment option for patients with musculoskeletal tumors, refractory to radiation therapy and systemic palliative therapies including chemotherapy, hormonal therapy, bisphosphonates, and analgesics. ${ }^{14-23,30}$

The cytotoxic effects of cryoablation are mediated through the formation of intracellular ice crystals during probemediated temperature manipulation. The crystals cause denaturation of proteins and shearing of intracellular structures, including cell membrane rupture. A liquid gas, commonly argon, is used to rapidly cool the tip of the cryoprobe, forming an enlarging ice-ball with time followed by a "thawing" phase, commonly achieved with helium gas, resulting in an osmotic gradient. ${ }^{33}$ The osmotic gradient causes water to rush into, swell, and then burst the tumor cell, eventually leading to cell hypoxia via indirect ischemic injury. ${ }^{34}$

Investigators have reported scattered cases of spinal metastases treated with percutaneous cryoablation as part of larger series of patients ablated for extraspinal musculoskeletal metastatic disease or as case series. ${ }^{14,18,20,23,26}$ In 2006, Callstrom et al ${ }^{14}$ reported 3 spinal tumors ( 2 in the sacrum and 1 in the lamina) as part of a 14-patient study managed effectively by cryoablation. As part of a multicenter prospective single-arm clinical trial of 61 patients who underwent image-guided cryoablation for the palliation of painful osseous metastases, Callstrom et $\mathrm{al}^{18}$ reported 6 spinal tumors ( 5 in the sacrum and 1 in the vertebral body), which were effectively palliated with significant decreases in pain and subjective improvement in the quality of life at $1,4,8$, and 24 weeks following the procedure.

Kurup et $\mathrm{al}^{20}$ reported a case series of 6 patients with sacrococ-

AJNR Am J Neuroradiol 37:189-95 Jan 2016 www.ajnr.org 
cygeal metastases who underwent imaging-guided cryoablation and suggested that cryoablation may be a safe and relatively effective technique for the management of recurrent sacrococcygeal neoplasms for local control or palliation of pain with short-term follow-up. In 2014, Prologo el $\mathrm{al}^{23}$ reported 2 patients with pedicle lesions as part of larger series of 50 patients with musculoskeletal metastases managed by cryoablation for pain palliation. Subsequently, in 2014, Kurup et $\mathrm{al}^{26}$ reported the utility of motorevoked potential monitoring during cryoablation of musculoskeletal tumors in 52 patients. The authors reported cryoablation in 27 spine and 3 sacral tumors, which were monitored by motorevoked potentials. However, the effectiveness of cryoablation for pain palliation and local tumor control was not discussed. ${ }^{26}$

In a retrospective analysis of data from patients with single vertebral metastasis, Masala et $\mathrm{al}^{19}$ described the safety and efficacy — through reduced pain (Visual Analog Scale scores) and disability (Oswestry Disability Index) — of cryoablation combined with vertebroplasty for the palliation of painful vertebral metastases, which was at least equivalent to vertebroplasty alone. However, the safety and efficacy of cryoablation as an exclusive treatment approach could not be evaluated because vertebroplasty was performed in all cases.

To our knowledge, this is the first single-center review describing the safety and effectiveness of cryoablation as the exclusive thermal ablation technique for local tumor control and palliation of painful spinal osteoblastic and osteolytic metastatic disease. The present study data suggest that percutaneous cryoablation is safe and effective for vertebral local tumor control and palliation of painful spine metastases. There was statistically significant pain palliation reflected by a substantial decrease in postprocedural NRS scores and analgesic use. Two patients (2 lesions) had persistent but improved pain following cryoablation. Local tumor control, evidenced by no radiographic evidence of active tumor at treated sites, was achieved in 96.7\% (30/31 lesions) of lesions on the basis of postprocedural cross-sectional imaging. One patient with sacral metastases did not benefit from the procedure and developed progression of disease despite technically adequate cryoablation.

The safety of the procedure was supported by a lack of major complications and only 2 minor transient complications based on the Society of Interventional Radiology guidelines. ${ }^{29}$ Thermal protection measures should be implemented in all spine cryoablations to ascertain safety before the procedure. In the current study, these techniques included neuroforaminal thermal monitoring with epidural or neuroforaminal injection of carbon dioxide or warmed $5 \%$ dextrose water; thermal isolation of critical abdominal and pelvic soft tissues, including by intraprocedural injection of carbon dioxide; and cutaneous thermal protection by surface application of warm saline during freezing cycles. In addition, intraprocedural motor-evoked potential monitoring was performed during a single ablation performed with the patient under general anesthesia. ${ }^{26,27}$

The efficiency of cryoablation for the treatment of osteoblastic spine metastases has not been studied previously. Radiofrequency ablation is rendered ineffective for the treatment of sclerotic metastases due to high impedance levels in attenuated bone. Cryoablation is emerging as an attractive alternative to RFA for palli- ation of sclerotic metastases. In 2011, de Freitas et $\mathrm{al}^{30}$ reported the effectiveness of cryoablation in a single patient with T9 and sacral osteoblastic metastatic disease. In the current study, 9 osteoblastic vertebral metastases were effectively palliated.

Nerve roots are more vulnerable to potential thermal injury with cryoablation compared with RFA, due to less tissue sensitivity to cold versus heat. This limitation is mitigated by implementation of thermoprotection techniques with the patient under conscious sedation and the use of sensory and motor-evoked potential monitoring with general anesthesia. In addition, posterior central vertebral body lesions are more challenging to access via a transpedicular approach by using straight cryoprobes.

The major limitation of the present study is the single-arm nature of the analysis with no control group and the lack of comparison to other treatment modalities, specifically radiation therapy. Additional limitations of the present study include its retrospective methodology, use of NRS scores for pre- and postprocedural pain assessment versus the more inclusive Brief Pain Inventory, and the relatively small number of palliated tumors.

\section{CONCLUSIONS}

Our safety and efficacy spine cryoablation results are commensurate with published studies of image-guided cryoablation in the setting of painful extraspinal musculoskeletal metastatic disease and may have contributory value in establishing the reproducibility of these procedures for pain palliation and local tumor control of vertebral metastatic disease. Additional work including prospective randomized studies of this therapy versus the historic standard of care, radiation therapy, will be valuable to further establish the efficacy of spine cryoablation for management of spine metastatic disease.

Disclosures: Adam Wallace-UNRELATED: Grants/Grants Pending: McDonnell Center for Systems Neuroscience, ${ }^{*}$ Comments: pending $\$ 40,000$ grant to study normal cerebral vasculature and blood flow across the lifespan; pending grants to be supplied with radiofrequency ablation probes (Dfine, San Jose, California), cryoablation probes (Galil Medical, St. Paul, Minnesota), and microwave ablation probes (Covidien, Irvine, California) for an animal study. Travis J. Hillen-UNRELATED: Payment for Lectures (including service on Speakers Bureaus): Dfine, Comments: lectures at cadaver labs; Other: Dfine, Comments: paid for proctoring cadaver labs. Jack W. Jennings - UNRELATED: Consultancy: Dfine; Payment for Lectures (including service on Speakers Bureaus): Dfine. *Money paid to the institution.

\section{REFERENCES}

1. Boland PJ, Lane JM, Sundaresan N. Metastatic disease of the spine. Clin Orthop Relat Res 1982;169:95-102 Medline

2. Harrington KD. Metastatic disease of the spine. J Bone Joint Surg Am 1986;68:1110-15 Medline

3. Wong DA, Fornasier VL, MacNab I. Spinal metastases: the obvious, the occult, and the impostors. Spine (Phila Pa 1976) 1990;15:1-4 CrossRef Medline

4. Lutz S, Berk L, Chang E, et al. Palliative radiotherapy for bone metastases: an ASTRO evidence-based guideline. Int J Radiat Oncol Biol Phys 2011;79:965-76 CrossRef Medline

5. Tong D, Gillick L, Hendrickson FR. The palliation of symptomatic osseous metastases: final results of the study by the Radiation Therapy Oncology Group. Cancer 1982;50:893-99 CrossRef Medline

6. Rosenthal D, Callstrom MR. Critical review and state of the art in interventional oncology: benign and metastatic disease involving bone. Radiology 2012;262:765-80 CrossRef Medline

7. Hara S. Opioids for metastatic bone pain. Oncology 2008;74(suppl 1):52-54 CrossRef Medline 
8. Gangi A, Kastler B, Klinkert A, et al. Injection of alcohol into bone metastases under CT guidance. J Comput Assist Tomogr 1994;18: 932-35 CrossRef Medline

9. Groenemeyer DH, Schirp S, Gevargez A. Image-guided percutaneous thermal ablation of bone tumors. Acad Radiol 2002;9:467-77 CrossRef Medline

10. Callstrom MR, Charboneau JW, Goetz MP, et al. Painful metastases involving bone: feasibility of percutaneous CT- and US-guided radio-frequency ablation. Radiology 2002;224:87-97 CrossRef Medline

11. Hillen TJ, Anchala P, Friedman MV, et al. Treatment of metastatic posterior vertebral body osseous tumors by using a targeted bipolar radiofrequency ablation device: technical note. Radiology 2014;273: 261-67 CrossRef Medline

12. Goetz MP, Callstrom MR, Charboneau JW, et al. Percutaneous image-guided radiofrequency ablation of painful metastases involving bone: a multicenter study. J Clin Oncol 2004;22:300-06 CrossRef Medline

13. Dupuy DE, Liu D, Hartfeil D, et al. Percutaneous radiofrequency ablation of painful osseous metastases: a multicenter American College of Radiology Imaging Network trial. Cancer 2010;116: 989-97 CrossRef Medline

14. Callstrom MR, Atwell TD, Charboneau JW, et al. Painful metastases involving bone: percutaneous image-guided cryoablationprospective trial interim analysis. Radiology 2006;241:572-80 CrossRef Medline

15. Gangi A, Buy X. Percutaneous bone tumor management. Semin Intervent Radiol 2010;27:124-36 CrossRef Medline

16. Thacker PG, Callstrom MR, Curry TB, et al. Palliation of painful metastatic disease involving bone with imaging-guided treatment: comparison of patients' immediate response to radiofrequency ablation and cryoablation. AJR Am J Roentgenol 2011;197:510-15 CrossRef Medline

17. Castañeda Rodriguez WR, Callstrom MR. Effective pain palliation and prevention of fracture for axial-loading skeletal metastases using combined cryoablation and cementoplasty. Tech Vasc Interv Radiol 2011;14:160-69 CrossRef Medline

18. Callstrom MR, Dupuy DE, Solomon SB, et al. Percutaneous imageguided cryoablation of painful metastases involving bone: multicenter trial. Cancer 2013;119:1033-41 CrossRef Medline

19. Masala S, Chiocchi M, Taglieri A, et al. Combined use of percutaneous cryoablation and vertebroplasty with $3 \mathrm{D}$ rotational angiograph in treatment of single vertebral metastasis: comparison with vertebroplasty. Neuroradiology 2013;55:193-200 CrossRef Medline

20. Kurup AN, Woodrum DA, Morris JM, et al. Cryoablation of recur- rent sacrococcygeal tumors. J Vasc Interv Radiol 2012;23:1070-75 CrossRef Medline

21. McMenomy BP, Kurup AN, Johnson GB, et al. Percutaneous cryoablation of musculoskeletal oligometastatic disease for complete remission. J Vasc Interv Radiol 2013;24:207-13 CrossRef Medline

22. Masala S, Schillaci O, Bartolucci AD, et al. Metabolic and clinical assessment of efficacy of cryoablation therapy on skeletal masses by 18F-FDG positron emission tomography/computed tomography (PET/CT) and visual analogue scale (VAS): initial experience. Skeletal Radiol 2011;40:159-65 CrossRef Medline

23. Prologo JD, Passalacqua M, Patel I, et al. Image-guided cryoablation for the treatment of painful musculoskeletal metastatic disease: a single-center experience. Skeletal Radiol 2014;43:1551-59 CrossRef Medline

24. Saliken JC, McKinnon JG, Gray R. CT for monitoring cryotherapy. AJR Am J Roentgenol 1996;166:853-55 CrossRef Medline

25. Daut RL, Cleeland CS, Flanery RC. Development of the Wisconsin Brief Pain Questionnaire to assess pain in cancer and other diseases. Pain 1983;17:197-210 CrossRef Medline

26. Kurup AN, Morris JM, Boon AJ, et al. Motor evoked potential monitoring during cryoablation of musculoskeletal tumors. J Vasc Interv Radiol 2014;25:1657-64 CrossRef Medline

27. Tsoumakidou G, Garnon J, Ramamurthy N, et al. Interest of electrostimulation of peripheral motor nerves during percutaneous thermal ablation. Cardiovasc Intervent Radiol 2013;36:1624-28 CrossRef Medline

28. Gordon DB, Stevenson KK, Griffie J, et al. Opioid equianalgesic calculations. J Palliat Med 1999;2:209-18 CrossRef Medline

29. Goldberg SN, Charboneau JW, Dodd GD 3rd, et al; International Working Group on Image-Guided Tumor Ablation. Image-guided tumor ablation: proposal for standardization of terms and reporting criteria. Radiology 2003;228:335-45 CrossRef Medline

30. de Freitas RM, de Menezes MR, Cerri GG, et al. Sclerotic vertebral metastases: pain palliation using percutaneous image-guided cryoablation. Cardiovasc Intervent Radiol 2011;34(suppl 2):S294-99 CrossRef Medline

31. Mercadante S, Fulfaro F. Management of painful bone metastases. Curr Opin Oncol 2007;19:308-14 CrossRef Medline

32. Goblirsch MJ, Zwolak PP, Clohisy DR. Biology of bone cancer pain. Clin Cancer Res 2006;12(20 pt 2):6231s-35s CrossRef Medline

33. Gage AA, Baust JG. Cryosurgery for tumors. J Am Coll Surg 2007; 205:342-56 CrossRef Medline

34. Theodorescu D. Cancer cryotherapy: evolution and biology. Rev Urol 2004;6(suppl 4):S9-S19 Medline 